\title{
Fundamentos para un estudio del guion en el cine chileno: notas preliminares
}

\section{A Theoretical Frame for a Study of the Script in the Chilean Cinema: Preliminary Notes}

\author{
Rubén Dittus Benavente \\ Escuela de Periodismo, Universidad Católica de la Santísima Concepción. \\ Concepción, Chile. \\ rdittus@ucsc.cl
}

\section{Resumen}

El artículo presenta el marco teórico para estudiar los modelos de guion en el cine chileno de ficción. La literatura publicada y el creciente interés en la formación de guionistas en la industria audiovisual, tanto en Chile como en el extranjero, dan cuenta de la necesidad de abordar los principios dramatúrgicos y los estándares profesionales desde una mirada integradora, que supere los clásicos modelos de escritura creativa. Más allá de las divergencias o acuerdos de dichas teorías, el guionista - por aceptación o negación- pareciera que no puede obviar las influencias de algunas reglas básicas de estructura narrativa.

Palabras clave: guion, cine chileno, dramaturgia, escritura creativa.

\begin{abstract}
The article presents the theoretical frame to study the models of script in the Chilean cinema. The literature published and the increasing interest in the scriptwriters' formation in the audio-visual industry, both in Chile and in foreigner, realize of the need to approach the dramaturgy and the professional standards from an of integration vision, which it overcomes the classic models of creative writing. Beyond the differences or agreements of the above mentioned theories, the scriptwriter -for acceptance or denial- seemed that it cannot obviate the influences of any basic rules of narrative structure.
\end{abstract}

Keywords: Script, Chilean cinema, Dramaturgy, Screenwriting. 
Contrario a lo que pudiera pensarse, la escritura del guion tiene más de cinco mil años de existencia (Carriere y Bonitzer, Práctica del guion cinematográfico). Con el cine y la televisión ha tomado una forma nueva, sujeta a exigencias técnicas y sobre todo al montaje, pero se remonta a las más antiguas formas de narración, como el teatro o el cuento. Desde su origen, no han faltado los consejos. Para varios investigadores, los guionistas son los descendientes activos de aquellos narradores. Hoy en día, sin embargo, esos escritores están expuestos a las normas y a la "eficacia" de las estructuras. El responsable pareciera ser Hollywood. El predominio que la industria cinematográfica de Estados Unidos ejerció desde mediados de los años ochenta favoreció la adopción de técnicas narrativas que pudieran lograr el éxito rápido. El guion no escapó a los cálculos comerciales de la empresa del entretenimiento. Así, la estructura en tres actos del conocido maestro de guiones, el norteamericano Syd Field - "el paradigma” - se convirtió en las tablas de la ley del cine de Hollywood. “¿Por dónde empieza el guionista?" es la pregunta con la que Field inicia su libro El manual de guionista (15). El texto está repleto de fórmulas y lugares comunes. El objetivo no es otro que facilitarle el trabajo a quien debe poner en el papel lo que será una futura película. Field escribe sobre procesos, temas, estructura, acción y personajes. También dice que siempre hay un punto de partida. Que todo guion surge de una idea que se modifica paso a paso. Escribe sobre los tres actos aristotélicos y promueve su tesis del paradigma. Insiste una y otra vez que toda historia debe ir hacia adelante, hacia la resolución. Field, además, sugiere ejercicios y “experiencias de aprendizaje”, como el propio autor reconoce: "Es una propuesta empírica. Cuanto más haga, mejor lo hará; es como nadar o andar en bicicleta" (10), enfatiza. El manual es una guía de escritura, o pretende serlo. ¿Por qué un profesor de guiones como Field decide escribir un libro que enseña las técnicas del buen escribir? Y sobre todo, ¿por qué enseñar un modelo que sólo ha tenido éxito en talleres tutoriales y presenciales? ¿Por qué pretender que hay una fórmula para la escritura de un guion que puede adquirirse en librerías o bajarse de Internet? Nada de eso tiene sentido si es que el autor no ha constatado una necesidad. El deseo como una fórmula mágica que busca bocetos coherentes y relatos predecibles.

El renombrado profesor español de guiones, Daniel Tubau, desarrolla su tesis de que otro guion es posible (Tubau, El guion del siglo veintiuno 2011). Nos dice que en el terreno de la formación de guionistas y los manuales de guion se puede hacer una investigación comparando los ejemplos de películas empleados por los autores, como una forma de revelar sus argumentos metodológicos. Si se comparan los cuatro clásicos de la teoría del guion como El manual del guionista (1979) de Syd Field, El viaje del escritor (1998) de Christopher Vogler, Cómo convertir un buen guion en un guion excelente (1987), de Linda Seger, y El guion (2002) de Robert McKee con los manuales que proponen teorías alternativas, hay diferencias llamativas. Según Tubau, en estos últimos se observa una mayor presencia de películas no anglosajonas, mayor presencia de clásicos de Hollywood y de los años sesenta y menos éxitos del momento. 
Lo que no está estudiado es si en las aulas universitarias y talleres independientes esas nuevas estructuras narrativas tienen el mismo nivel de influencia. Ello constata la necesidad de superar realidades como la hollywoodense, donde todo aparenta ser sólo una fábrica de sueños. El cine que se ha desarrollado alejado de esa industria tiene sus propios desafíos en el contexto de la globalización y donde la lucha por marcar presencia en los festivales del área se hace mucho más notoria que antaño. Si es ese el camino de las artes audiovisuales en nuestra región, es paradójico el escaso interés por estudiar la estructura de una narrativa que tiene sus propios tiempos y protocolos. El estudio del guion en el cine chileno no forma parte de la tradición de las actividades asociadas a la industria audiovisual. Un reciente estudio llevado a cabo sobre el campo de la investigación cinematográfica (Stange y Salinas "Hacia una elucidación”) deja en evidencia la desarticulación de las prácticas al interior de un ámbito que se caracteriza por la heterogeneidad de sus docentes e investigadores y por una diversidad de procedencias y corrientes metodológicas. Se trata de un campo fragmentario, disperso e incompleto, en el cual rara vez se pone el acento en la generación de los contenidos de una empresa que debe competir de igual a igual con las producciones foráneas. En la mayoría de los casos se limita a abordar estudios estadísticos y técnicos sobre la acción de los mercados o la audiencia. Lo anterior no se condice con la necesidad de un diseño de políticas públicas que permitan potenciar una industria nacional sustentable y con producciones cinematográficas atractivas para el público chileno. No hay que olvidar que el cine se construye con una participación activa de todos los sectores integrados en redes de colaboración, donde la preocupación por la dimensión creativa sigue estando al debe.

No debe extrañar, entonces, la invitación a preguntarnos sobre el valor asignado a los estándares profesionales y los principios dramatúrgicos que se aplican en el proceso de escritura del cine chileno de ficción, parte de la dimensión productiva de la denominada "industria audiovisual chilena". Nos motiva la ausencia de una formación sistemática en escritura creativa, constituyéndose en la dimensión creativa menos profesional de toda la etapa de pre-producción de un filme. Los resultados cuantitativos de un estudio reciente (Dittus, "Radiografía del guionista chileno") indican que la teoría del guion está bastante presente, ya sea en cursos de universidades o institutos $(29,5 \%)$, talleres u otros cursos de formación $(26,2 \%)$ y la formación autodidacta $(32,8 \%)$. A pesar de dichas influencias, se reconoce que al momento de diseñar los lineamientos de un relato, no se recurre a alguna preferencia teórica, pues ello varía según el proyecto audiovisual (56,5\%). Es un dato clave que el grupo de directores y guionistas consultados no tenga experiencia académica o en tareas de formación hacia otros realizadores. Cuando se les pregunta sobre la última actividad asociada a la extensión o investigación en el área audiovisual, la mayoría indica la entrevista a un medio de comunicación (35\%), quedando más atrás las charlas (13,3\%), conferencias en una universidad o instituto $(18,3 \%)$ o ponencias en congresos o seminarios $(11,7 \%)$. Lo anterior repercute en la existencia de algún anclaje teórico específico o 
en algún autor con mayor ascendiente en el proceso creativo. Solo una menor parte de los encuestados indica que al momento de iniciar la escritura o de diseñar los lineamientos de un relato audiovisual recurre a una idea original basada en la biografía propia o la de cercanos $(22,6 \%)$ y a la teoría del conflicto central u otros modelos clásicos (12,9\%). La gran mayoría señala que ello varía según el proyecto audiovisual (56,6\%). Ello lleva consigo varias consecuencias, pero quizás la más relevante sea la invisibilidad de una dramaturgia creada al servicio de una actividad cinematográfica profesional. A partir de esta inquietud buscamos iniciar el debate sobre las orientaciones epistemológicas o modelos de escritura asumidos por los guionistas del cine chileno y definir, en futuros estudios, si existe una relación entre aquellas producciones más valoradas por los festivales de cine y por el público en las salas de exhibición con los modelos de escritura desarrollados.

\section{La economía de la cultura}

Partiremos desde un anclaje conceptual: el cine como parte constitutiva de la denominada economía de la cultura nos recuerda que no es ajeno a las dinámicas propias del mercado ni al valor del consumo que sus agentes e instituciones del Estado le asignan. La economía de la cultura "es una sub-disciplina de la ciencia económica que estudia la producción, distribución y consumo de todos los bienes y servicios culturales" (Towse, Manual de economía de la cultura) desde dos puntos de vista: "el análisis de aspectos económicos o materiales de las actividades artísticas" y "la aplicación al arte de la metodología económica (Frey, La economía del arte). Vinculada inicialmente al arte -ya que se restringía a las artes escénicas relacionadas con la alta cultura- los primeros estudios de esta nueva disciplina económica fueron publicados por Throsby en el Journal of Economic Literature (1994), y Blaug en el Journal of Economic Surveys (2001), donde los temas de análisis se concentraron en la formación del gusto por las artes, mercados de obras de arte, características de las artes escénicas, mercados de trabajo de los artistas, políticas públicas hacia las artes, e industria de las comunicaciones. Sólo a partir del 2003 se empezó a utilizar el término "economía de la cultura" como reflejo de la ampliación del ámbito de estudio hacia las artes escénicas (música, danza, ópera y teatro), artes visuales y plásticas (pintura, dibujo, fotografía, escultura, artesanía, etc.), artes literarias (poesía, ficción, teatro, guiones, y algunas formas de no ficción como la biografía), el cine y algunas prácticas nuevas como el video-arte que se derivan de las nuevas tecnologías de la información y la comunicación" (Durlauf y Lawrence, The New Palgrave Dictionary of Economics III). Más allá de la aplicación del análisis económico a los bienes y servicios culturales, hay un aspecto básico en el desarrollo de esta sub-disciplina, que constituye su piedra angular: los bienes y servicios artísticos y culturales tienen características especiales que distinguen su producción y consumo de los demás bienes. En lo concreto, se distinguen algunas particularidades del 
bien cultural tales como su expresividad como valor intangible o simbólico, el trabajo creativo que define su proceso productivo, el que sea individualmente insustituible y la incertidumbre sobre el resultado de su puesta en valor (Zallo "La economía de la cultura"). Dicha constatación es clave para entender el comportamiento de los consumidores, las empresas, los mercados y la acción del gobierno en el sector cultural, así como el papel que en la historia del pensamiento económico se ha atribuido a las actividades culturales (Durlauf y Lawrence The New Palgrave Dictionary of Economics III). En esta perspectiva, las problemáticas que enfrenta la economía de la cultura buscan reconocer y especificar las externalidades derivadas de la producción.

Hoy día, los ámbitos de aplicación de la economía de la cultura son más amplios y representan cada uno de los engranajes que ponen en funcionamiento la industria cultural, desde las clásicas artes visuales y escénicas hasta la publicidad, los video-juegos y el copyright. El crecimiento sostenido de la oferta, la producción y el consumo audiovisual, así como el surgimiento de un nuevo consumidor-espectador, han confirmado la tendencia mundial al crecimiento sostenido de un conjunto de procesos de convergencia económica y comercial, constituyéndose en parte esencial de un macro-sector de la economía: el mercado de las comunicaciones (Trejo Cine, neoliberalismo y cultura). La evidencia indica, sin embargo, que la economía de la cultura a menudo prescinde del cine como objeto de estudio, debido a la fragmentación del campo académico, donde se separan los estudios en humanidades y ciencias sociales, dejando en esta última categoría a los estudios sobre medios y comunicación con mayor penetración en los hogares, como Internet, la radio y la televisión (Wasko "La economía política del cine"). Ello ocurre porque los contenidos cinematográficos no se vinculan con la cadena multimedia generada por la producción de dicho capital simbólico. La información disponible se concentra en asistencia a salas, número de espectadores por película, ingresos brutos por recaudación de taquilla, distribución de la asistencia a las películas por regiones y la información respecto al producto audiovisual en sí. La economía de la cultura necesita la mayor cantidad de información posible respecto a qué pasa con los retornos de taquilla y la reputación de cada película estrenada para resolver los desafíos de producción. La escasa literatura producida por investigadores especializados tampoco ha logrado organizar perspectivas reconocibles en un campo donde el cine no aparece como un objeto de estudio sistemático (Stange y Salinas "Hacia una elucidación") ni como generador nítido de insumos para la dimensión productiva de la economía de la cultura. Uno de esos ámbitos se refiere a las condiciones que hacen óptimo el proceso creativo en la industria cinematográfica. Sin duda, esta última línea de investigación será un elemento fundamental en los próximos años (Palma, "Mercado del arte") El guion, como parte de la dimensión creativa en la etapa de pre-producción, representa uno de los ejemplos de la vulnerabilidad del mercado y cuya labor poco profesionalizante en países como Chile (por formación y dedicación) está lejos de ser comparada con otras industrias similares. 


\section{El guion como teoría}

Si bien el guion tiene algunas semejanzas con la literatura y el teatro, posee características propias que hacen que se estudie de manera independiente. Prueba de ello es el elevado número de libros y manuales académicos publicados y cursos o talleres que se dedican a la enseñanza y análisis del guion en universidades americanas y europeas. Se puede hablar, en consecuencia, de una ciencia del guion (Tubau, Las paradojas del guionista; Parker, Arte y ciencia del guion). Dichas aproximaciones, sin embargo, promueven la práctica y la escritura del guion, y no tanto su análisis científico, principal rasgo de las realidades académicas latinoamericanas. He aquí la primera paradoja. Desde los principios del cine se empezó a escribir de teoría del cine, pero esa producción intelectual es distinta en lo que a teoría del guion se refiere. En realidad, esta nace mucho antes, con el teatro. En efecto, los orígenes del guion no son ajenos a la dramaturgia, y por lo tanto el guionista aplica de ésta aquel conjunto de principios narrativos que buscan establecer un clima de interés progresivo entre la historia que se explicita y los espectadores que la reciben. De hecho, el término "dramaturgia" encierra en un sólo término el gran número de relatos y géneros narrativos y su relación con el público. Este vínculo no es antojadizo, ya que la raíz de cualquier proyecto cinematográfico es la necesidad de un realizador de expresar algo a alguien. El guionista construye la estructura, los personajes y los diálogos de sus obras pensando siempre en el carácter audiovisual del producto acabado. Para ello, debe tener en cuenta tanto el lenguaje cinematográfico como la peculiar manera en la que su discurso será recibido por la audiencia. Tal como explica Sánchez-Escalonilla: "el guion es aquel texto que desarrolla un argumento e indica cómo se debe realizar una obra audiovisual y que convierte al guionista en un escritor de imágenes". El Diccionario de la Real Academia Española lo define como "texto en que se expone, con los detalles necesarios para su realización, el contenido de un filme o de un programa de radio o televisión".

Uno de los principios dramatúrgicos más extendidos indica que quien escribe para cine debe conocer la especificidad del medio para el cual trabaja, tener en cuenta el proceso de producción de cada uno de los soportes y géneros y ponerse en el lugar del público a quien va destinado el producto audiovisual. En otras palabras, al escribir para el cine se ha de pensar no sólo en imágenes sino en los mecanismos de recepción de esa creación (Vanoye, Guiones modelos y modelos de guion 20). Estas consideraciones dan cuenta de una de las discrepancias en torno a la autoría del guion, rasgo que lo diferencia de la literatura o el teatro. Es decir, implica tener en cuenta que es un trabajo que se parece a la carpintería: "consiste básicamente en preparar un armazón que después otros pueden acabar como quieran [...] Escribir un guion es como hacer una cama a alguien, y después ese otro llega y se mete dentro de ésta y a ti lo único que te queda es volver a casa" (Billy Wilder, cit. en Aranda y de Felipe 21). En la misma línea lo plantea Theodor Dreyer, quien aun reconociendo que la elaboración de un guion es antes un asunto artístico que un problema técnico, el verdadero responsable de todo 
proyecto cinematográfico no es otro que el director, ya que "él es quien hace que se oiga la palabra del escritor [...] Él es quien crea los sentimientos y las pasiones que nos golpean y conmueven. Él es quien impregna la película con ese algo inexplicable que denomina estilo" (Aranda y de Felipe, Guion audiovisual 26). Esto confirma el carácter transitorio del guion (Carriere, Práctica del guion cinematográfico) pero no necesariamente su desvinculación de la literatura. Se trata de un objeto paradójico, ya que da cuenta de algo escrito, así como el libreto para el músico.

Una importante corriente teórica indica que el guion está lejos de ser una obra en sí misma; no obstante, desde los inicios mismos del cine se han usado las reglas fundadoras de la dramaturgia iniciadas por la tragedia y el teatro griego y las directrices postuladas en el manual dramatúrgico más antiguo de todos: la Poética de Aristóteles. En ella encontramos los elementos fundamentales para la comprensión del teatro trágico. Muchas de las diez mil palabras de la Poética no tienen relación con el drama; ninguna de ellas, obviamente, tiene que ver con el cine, pero su núcleo contiene una serie de ideas indispensables para cualquier dramaturgo o guionista actual: trama, personajes, conflicto, crisis, clímax, exposición y diálogo son algunos de los temas que se aluden en la obra aristotélica y que han sido profundizadas por nuevos autores. "Muchas de las frases y palabras de Aristóteles permanecen un tanto oscuras hoy, y tal vez lo fuesen para sus contemporáneos, pero su obra todavía constituye una obra de entendimiento no superada" (Blacker, Guía del escritor de cine y televisión 23). Por ejemplo, la teoría según la cual el conflicto transforma al protagonista aún es válida para la aplicación en los guiones cinematográficos. Es más, el interés del público decae si el problema no es lo suficientemente significativo como para cambiar la vida del protagonista. Cuando el autor impregna la obra de muchas situaciones secundarias y comienza a acumular detalles y situaciones que entorpecen, afectan a la idea central y esencial del relato. La unidad dramática es una de las herencias más destacadas de la tesis aristotélica en la estructura del guion. Aristóteles afirmaba que la fábula debía ser completa y perfecta, y una unidad compuesta por principio, desarrollo y final. Y como es la imitación de una acción plena y entera, es necesario que las partes sean reunidas de tal manera que si se saca una de ellas, el todo se mantenga en su unidad. En este punto, el juicio de Irwin Blacker -escritor y por más de veinte años profesor de escritura cinematográfica en la Universidad del Sur de California- es categórico:

el guionista aprende de los principios básicos de la dramaturgia. No existen reglas absolutas ni leyes, pero sí una tradición de 2.500 años de análisis dramático y miles de películas de los cuales esos principios pueden deducirse. Los estilos y convenciones en el drama ha cambiado desde los griegos pasando por la época Isabelina, la Victoriana y los Modernistas, tan influidos por Freud. Y, a pesar de que existen algunos guiones escritos como alternativa a esos principios, la teoría básica de la dramaturgia aristotélica aún no ha sido superada (Ibíd.). 
Esa influencia en cursos y manuales sigue vigente. Entre 2007 y el 2012 se han registrado más de cien nuevos libros sobre guion en la Biblioteca del Congreso de Estados Unidos. En una investigación chilena reciente (Brenes, "Buenos y malos personajes"; "Quoting and Misquoting") se estudiaron 68 de esos libros y otros 27 manuales de guion publicados desde 1979, fecha en la que apareció el texto de Syd Field, The Foundations of Screenwriting. La investigación efectuada exploró el alcance que tiene la Poética de Aristóteles en estos manuales, proponiendo que cabe una segunda lectura sobre la Poética, que no solo tome en cuenta su carácter didáctico y técnico, sino también su dimensión filosófica y sapiencial y, por tanto, el interés profesional para guionistas y espectadores. Hay que recordar que, en la noción aristotélica, la tragedia consta de seis partes: mito, personajes o caracteres, elocución, pensamiento, espectáculo y ritmo. Aristóteles sostiene que los personajes están al servicio del mito, que, como "alma de la tragedia", es "el patrón de sentido que rige u organiza el tiempo moral en que se desenvuelven los cambios que se operan en los personajes" (GarcíaNoblejas, Poética del texto audiovisual 14). Para Aristóteles el más importante de estos elementos es la estructuración de los hechos -el mito- porque la tragedia es imitación, no de personas, sino de una acción y de una vida, y la felicidad y la infelicidad están en la acción. El análisis de los manuales de guion demuestra que la mayor parte de las veces, la Poética de Aristóteles ha sido usada como un texto de referencia técnico enseñando a estructurar una historia, convirtiéndola en una fórmula "rígida" que debe ser asumida. Sin embargo, cuando el filósofo es estudiado y citado en su contexto, el sentido es otro, mucho más en concordancia con el proceso creativo que pueden ser tomados en cuenta tanto por el autor como por la audiencia. En otras palabras, el estudio mencionado propone una nueva lectura del texto Aristotélico -más humanista que técnico- que tiene en su esencia la idea de que la escritura es una actividad que recrea la vida humana (Brenes, "Quoting and Misquoting Aristotle's Poetics" 77).

En la actualidad, el teórico del guion más conocido es Robert McKee, quien imparte seminarios en todo el mundo y cuyos asistentes pagan por escucharle hablar. La tesis central del discurso de McKee (2002) es una abierta crítica al principio del paradigma, postulado por otro de los teóricos más respetados del arte y ciencia del guion: Syd Field. Este autor y otros teóricos del guion -siguiendo las enseñanzas de Aristóteles en el teatro griego- proponen un conjunto de herramientas y métodos que buscan facilitar el trabajo creativo de escritores y guionistas. Es decir, hay estructuras, tramas y detonantes de verosimilitud que conforman la figura del paradigma, tesis que McKee rechaza. Al respecto, señala: "cualquier teoría sobre los paradigmas y los modelos infalibles de redacción que sirven para alcanzar el éxito comercial es un disparate" (El Guion 33).

A pesar de la postura de McKee, el principio de la premisa es ampliamente aceptado por los teóricos del guion, dando forma a la figura del cuerpo narrativo. Se trata de concebir la escritura del relato cinematográfico como un proceso orgánico en el que participan varios subsistemas: los personajes, la trama, las revelaciones, el universo narrativo, el argumento mora, la trama escénica o el diálogo sinfónico 
(Truby, Anatomía del guion 27). Cada subsistema del relato consiste en una red de elementos que ayudan a definir y a diferenciar el resto de los elementos del sistema. En forma metafórica lo explica John Truby:

Podríamos decir que el tema, o lo que yo llamo el argumento moral, correspondería al cerebro de la historia; el personaje, al corazón y al sistema circulatorio; las revelaciones, al sistema nervioso; la estructura, a la historia, al esqueleto; y las escenas, a la piel (Anatomía del guion 20).

Esta estructura del guion busca mantener bajo control el código dramático, facilitando que el desarrollo escritural no se aleje del nivel profundo de la historia ni de la necesaria maduración motivada por el cambio y el conflicto, elementos considerados motores del guion. Por ejemplo, la teoría aristotélica según la cual el conflicto debe ser lo suficientemente grande como para transformar al personaje central aún es válida para su aplicación en los guiones cinematográficos. Pareciera que el interés del público decae si el problema no es lo suficientemente significativo como para cambiar la vida del protagonista (Blacker, Guía del escritor de cine y televisión 36). Así, la extensión apropiada de un drama se relaciona con la extensión y significado del conflicto. El principal efecto de este paradigma dramatúrgico es el ordenamiento que se postula para crear los acontecimientos.

El caso de Syd Field es emblemático en el estudio y enseñanza del guion en Estados Unidos. En 1979, tras leer guiones célebres y ver las que se consideran las mejores películas de la historia del cine, descubrió que había una estructura subyacente, a la que llamó "paradigma”. El paradigma de Field sostiene que el guion se tiene que dividir en tres actos, que es lo mismo que descubrió Aristóteles al examinar las obras del teatro de la Grecia clásica. Ahora bien, nos dice Field, además de estos tres actos, en todo buen guion ha de existir lo que se llama plot point, punto de giro o nudo de la trama, alrededor de la página 25: "un nudo de la trama es un incidente, episodio o acontecimiento que se engancha a la acción y la hace tomar otra dirección, entendiendo por dirección una línea de desarrollo" (El manual del guionista 25), y cuya función es hacer avanzar la historia y hacer coherente la estructura de los tres actos. Field logra identificar en sucesivas lecturas de guion dos pinzas en el segundo acto. La pinza es algo que mantiene sujeta la historia. Escribe Field: "la primera pinza aparece alrededor de la página 43 de la primera mitad y la segunda, alrededor de la página 75 . Una pinza puede ser una escena, una secuencia o un nudo de la trama" (El libro del guion 21). De esta manera, el paradigma de Field ha sido durante mucho tiempo el modelo al que se tenía que ajustar un guion made in Hollywood, seguido por autores como Linda Seger y Elliot Grove. Seger insiste en una estructura en tres actos, aunque en su opinión, el tercer acto ha de durar treinta páginas, dedicándose las cinco últimas a una breve resolución que "ate los cabos sueltos" (Cómo convertir 18). Grove, por su parte, postula la estructura de nueve pasos, identificados en las páginas $1,3,10,30,45,60,75$ y 90, es decir, con momentos importantes o puntos de giro que impulsan el relato cada quince o veinte minutos. 
Todas esas referencias dramatúrgicas han sido complementadas desde mucho antes por la tesis que el investigador ruso Vladimir Propp expone en su texto Morfología del cuento. Publicada por primera vez en 1928, este análisis de los relatos ocupa un lugar central en los análisis narratológicos contemporáneos. El detallado estudio de cien cuentos maravillosos del folclore ruso permitió al autor identificar la matriz originaria desde donde han surgido todas las restantes estructuras narrativas. Entre las conclusiones, el estudio indica que el cuento reproduce rituales que señalan ese tránsito entre infancia y adultez. Metafóricamente hablando, dejamos de ser pacientes para convertirnos en agentes o sujetos de acción. Propp -a través de un método deductivo-identificó 31 funciones permanentes en los personajes, "sean cuales fueren esos personajes y sea cual fuera la manera en que se realizan esas funciones [...] cuentos que pertenecen al mismo tipo en lo que respecta a su estructura" (Morfología del cuento 24). Los estudios literarios y semiológicos (Barthes, Análisis estructural del relato; Greimas, Semántica estructural) reconocen y simplifican gran parte de estas funciones como características reconocibles en relatos de ficción como la telenovela (Valenzuela, Taller de escritura de telenovelas). A partir de esas funciones se ha establecido a nivel teórico diferentes etapas del denominado "viaje mítico", tesis que postula Joseph Campbell en sus libros El poder del mito y Las mil caras del héroe. Dichos trabajos examinan cientos de mitos y leyendas, encontrando un patrón que se repite en muchas historias: el viaje del héroe. Dicho modelo narrativo tiene un alcance universal, al igual que la teoría de los arquetipos del psicólogo suizo Carl Jung, en el que se observa una constante repetición de ciertos caracteres o energías que acontecen en los sueños, así como en los mitos de todas las culturas. En la década de los noventa, el analista de guiones Christopher Vogler, que trabajaba en Disney Corporation, decidió analizar en detalle las ideas de Campbell en algunos ejemplos de películas clásicas y de reciente estreno. Dicho trabajo circuló en los estudios Disney en un informe de siete páginas llamado Guía práctica de "El poder del mito", que años más tarde serviría de base para el libro El viaje del escritor. En ese texto, Vogler ofrece un esquema del llamado viaje del héroe que, en su opinión, se puede aplicar a cualquier narración, incluidos los guiones de Hollywood. Para probarlo, analiza películas como Titanic, Pulp Fiction, El rey León, Full Monty y La guerra de las galaxias, considerada esta última como el más nítido ejemplo de la aplicación del modelo de Campbell en el cine.

Campbell había descifrado el código secreto de las historias. Su obra se erigió en una suerte de llamarada que súbitamente iluminó un paisaje que se hallaba sumido entre las sombras. Trabajé con la idea de Campbell relativa al viaje del héroe para entender el fenomenal ejercicio de repetición que ponía en práctica la industria cinematográfica en películas tales como La guerra de las galaxias y Encuentros en la tercera fase [...] El poder del mito constituyó una especie de salvavidas cuando inicié mi trabajo como analista de historias para los grandes estudios de cine (El viaje del escritor 33). 
Según Campbell (El héroe de las mil caras 1984), existen doce fases claras delimitadas de lo que se entiende como viaje mítico, las que coinciden -estando éstas agrupadas- con la estructura de los tres actos que proponen muchos teóricos del guion: (1) el mundo ordinario, (2) la llamada de la aventura, (3) el rechazo de la llamada, (4) el encuentro con el mentor, (5) la travesía del primer umbral, (6) pruebas, aliados y enemigos, (7) la aproximación a la caverna más profunda, (8) la odisea, (9) la recompensa, (10) el camino de regreso, (11) la resurrección, y (12) el retorno con el elixir (El héroe de las mil caras 45). La aplicación del modelo de Campbell no tiene por qué realizarse en películas en las que hay grandes batallas espaciales o luchas contra monstruos, sino a cualquier historia imaginable donde el personaje principal deba abandonar un mundo ordinario para iniciar una aventura, generando un contraste con un mundo extraordinario (El poder del mito 24). Para la teoría dramatúrgica, cada narrador ajusta el modelo mítico a los rasgos y peculiaridades de su propósito o a las particularidades de cada cultura.

Un estudio reciente que buscó reconocer la aplicabilidad comparativa del modelo de Campbell en el análisis de tres películas chilenas de diverso género y de reciente estreno, dio cuenta que el viaje mítico se bosqueja como un esqueleto que puede ser enriquecido por los guionistas de ficción, con la libertad para suprimir etapas o alterar el orden de éstas. Se convierte, así, en un modelo extremadamente flexible que permite múltiples variaciones donde lo importante es la figura de un personaje que es llamado a la aventura y sobrevive gracias a un festival de arquetipos reconocibles (Dittus, "El viaje del héroe en el cine chileno actual"). En el análisis de los filmes $\mathrm{La}$ Nana (Sebastián Silva 2009), Baby Shower (Pablo Illanes 2011) y No (Pablo Larraín 2012) observamos que es el llamado a la aventura es el que establece las reglas del juego narrativo y define el objetivo del héroe:

Lo que está en suspenso se suele plantear en forma de pregunta: ¿Podrá el publicista doblar la mano al establishment político? ¿Podrá la nana encontrar respuesta a sus dudas y enfrentar su verdadero miedo interior? ¿Triunfará la venganza sobre las víctimas del despecho?, son algunas de las preguntas que surgen en estos viajes a mundos desconocidos. Una vez que los aliados y enemigos se expresan y se inicia el camino de retorno, siempre la resurrección transforma al héroe, tanto que regresa a su mundo anterior convertido en un nuevo ser (7).

\section{La teoría dramatúrgica en Chile}

Algunos dramaturgos y cineastas chilenos han hecho suya la teoría del conflicto central y otros aspectos del estudio teórico, ya sea para aprovecharlos o cuestionarlos. Orlando Lubbert, cineasta y profesor universitario, en una de las pocas publicaciones chilenas dedicadas al guion, da cuenta de la importancia del punto de vista como camino para los grandes temas hechos cine. "La misma idea en su origen ya viene contaminada 
con una intención" (Guion para un cine posible 20). Sólo con el punto de vista, el mecanismo de creación desde el imaginario se activa, dice Lubbert, haciendo que el guionista construya sus propias imágenes de la manera más arbitraria:

El mecanismo de la mente creando imágenes que se adelantan a los hechos es algo que podemos comprobar en nosotros mismos. En un artículo científico leí sobre esto y lo que más me sorprendió fue saber que se ha probado que, luego, al archivarse en nuestra memoria, ambas imágenes se mezclan la creada por nosotros y la real (21).

De esta forma, el autor pone énfasis en que todo oficio -incluido el de guionistautiliza este mecanismo imaginario para facilitar el proceso de creación aun cuando nunca hayamos estado en el lugar que relatamos o bosquejamos. El autor no esquiva la incómoda presencia del mercado como co-guionista. En palabras de Lubbert, es una premisa disfrazada de cálculo. Se trata de aquellas temáticas o personajes como recursos narrativos o audiovisuales que delatan el oportunismo del realizador: una belleza femenina bien dotada o las predecibles escenas de violencia para dejar satisfecho al más sórdido morbo espectatorial: "Desde el punto de vista narrativo la violencia, el erotismo, la pasión, por ejemplo, dejan de obedecer a necesidades de la historia para descontextualizarse y convertirse en impostación", recalca (Lubbert 130).

El caso del dramaturgo Benjamín Galemiri es el que más se acerca al modelo norteamericano. Basándose en la teoría de los actos de Aristóteles y respetando los modos de narración lineal y atómico, enseña su propio modelo de creación de guiones, teniendo a la premisa como recurso creativo. Para Galemiri, la premisa es una herramienta dramatúrgica útil para la construcción de personajes con ciertos niveles de profundidad que alimentan el avance de la historia. Una premisa es una idea que se toma de base para un razonamiento que nos permite inferir algo y sacar una conclusión. Puede ser verdadera o falsa, objetiva o subjetiva, y lo importante es plantearla al inicio del ejercicio escritural. Para Galemiri dicho planteamiento permitirá al guion lograr un alcance filosófico, haciendo que la obra logre su perdurabilidad en el tiempo y lugar, con temáticas que seguirán vigentes. A través de ese "levantamiento del mundo autoral", el dramaturgo busca generar películas con personalidad y rasgos propios, que vayan más allá de lo puramente visual y sepan expedir un mensaje:

Aplicando la historia oculta (de lo que el autor quiere hablar verdaderamente) se sustentará el mundo interior que contendrá la película y al aplicar la premisa se sustentará la construcción de los personajes, estableciéndose el lugar del habla de cada uno de ellos, lo que contribuye directamente a profundizar el nivel de los diálogos (Guion: dramaturgia para el cine 11).

Es a partir de ese trabajo autoral que Galemiri presenta su propio modelo de creación para diversos formatos narrativos (teatro, cuento, novela, guion), concebido en cinco pasos que dibujan un esquema como un mapa de elementos que luego deberán con- 
siderar las escenas de la película. El esquema de las "cinco hojas paradigmáticas" se explica como sigue: (1) presentación de los personajes (2), los personajes expresan sus voluntades, (3) las voluntades entran en colisión, (4) explota el conflicto, y (5) se produce el desenlace, en el que aparentemente todo sigue igual, pero en el fondo todo ha cambiado y nada vuelve a ser como antes. El modelo de Galemiri adecua la fórmula que indica que las historias malas son aquellas que están mal construidas. El objetivo, dice, es levantar una especie de mapa dramatúrgico personal que permita dibujar mundos y personajes, para luego deshacer, desordenar, volver a armar y encontrar un orden nuevo. "Lo importante, como en todo tipo de arte, es fijarse en los detalles, sobre todo en lo inconsciente (carga biográfica del autor), que es lo que más personalidad otorga. Sin esos rasgos, sean pragmáticos o no, nos queda un producto impersonal" (12).

Mención aparte merece la concepción de guion del destacado realizador y semiólogo Raúl Ruiz quien evoca críticamente el enunciado de la teoría del conflicto central: "Una historia tiene lugar cuando alguien quiere algo y otro no quiere que lo obtenga. A partir de ese momento, a través de diferentes digresiones, todos los elementos de la historia se ordenan alrededor de ese conflicto central" (Poéticas del cine 17). Ruiz no tarda en considerar lo que llama la inaceptable relación entre la voluntad y el pequeño juego de estrategias y de tácticas, pues afirmar -dice él- que una historia que no puede existir sino en razón de un conflicto central, nos obliga a eliminar todas aquellas otras que no incluyen ninguna confrontación, dejando de lado los acontecimientos a los que somos indiferentes o sólo despiertan en nosotros una vaga curiosidad, tales como un paisaje, una tormenta lejana o una cena entre amigos. Esa imposición hegemónica es lo que rechaza como principio creativo: "Lo cierto es que tal teoría posee todos los elementos para ser calificada de irrefutable, en la medida en que no puede ser probada ni tampoco puesta en entredicho" (22).

La opinión crítica del más internacional de los cineastas chilenos es coherente con su interés de filmar todo lo que está fuera del guion, "que es como trabajan los músicos orientales, que tienen una partitura [...] Ellos tocan todo menos la partitura" (Ruiz, cit. en Buci-Glucksmann 36). Es la razón por la que Ruiz valora mucho más el guion en un documental que en la ficción, ya que sólo una vez que se interviene en el territorio se definen las prioridades de la historia. La eficacia de Ruiz en la construcción de relatos audiovisuales se sostiene a partir de los conceptos de filme secreto y de guion múltiple. Con el primero, el realizador asegura que siempre habrá una ficción dentro de otra ficción. Se trata de una especie de historia escondida que se aleja de la figura aristotélica de la fábula. Son los gestos e imágenes de gestos al interior de un filme los que sostienen el relato completo, por lo que cualquier estructura compleja del mismo es inoficiosa y predecible. En ese sentido, Ruiz se aleja del camino regular para dar forma al relato audiovisual. "Escribo muchos guiones y los voy mezclando" (Entrevistas escogidas 117), dice Ruiz en una entrevista, graficando la manera cómo opera la dinámica de su creación. Un juego combinatorio y yuxtaposición de múltiples 
guiones que aseguran que siempre habrá una historia escondida dentro de la trama general. El enigma no es ajeno a la filmografía de Ruiz. Su presencia es recurrente y termina por construir otra película al interior del filme. Ruiz nos invita a desacralizar el guion y entenderla como una ficción momentáneamente útil, pero desde el momento que pierde utilidad es reemplazada por otra ficción. Su modelo se retrata en la siguiente opinión cuando se le pregunta sobre sus ideas en torno a la ficción en su película Las almas fuertes (2001):

Mucho antes de Las almas fuertes, yo había comenzado a trabajar desde el punto de vista teórico en una idea muy simple. Se trataba de aceptar y de hacer literal la idea de que en una película cada plano es una película en sí. ¿Cuáles son las consecuencias de esta idea, y del hecho de que cada plano esté conectado con otro? Empecé a estudiar entonces únicamente la noción de plano, lo que ocurre en el momento en que decimos “¡Acción!” y el momento que decimos “ ¡Corten!”. En cada plano existe o subsiste un determinado número de funciones que me es posible estructurar de maneras distintas [...] Tenemos tan poco tiempo para filmar, podemos hacer tan pocas películas y, finalmente, resulta tan complicado, que es estúpido hacer una sola a la vez: habrá que crear una docena o una quincena en cada una (Ruiz, Entrevistas escogidas 159).

El método de Ruiz busca la proliferación de narrativas divergentes y ramificadas (Sánchez, Aventura del cuerpo 25). Ese cruce de historias sólo es posible a través de un modelo laberíntico capaz de contar dos o más historias a partir de una. Con el cine Raúl Ruiz es imposible contar una sola historia. Esta lógica diferente consolida la relación escondida de lo subjetivo y objetivo a la vez y de lo real y lo irreal, donde se potencia la dimensión contraria.

\section{A modo de conclusión}

Más allá de las divergencias o acuerdos, las teorías del conflicto central y de los tres actos dan cuenta de la existencia de un dispositivo dramatúrgico que ordena y orienta el trabajo creativo en la industria cinematográfica (Dittus, "El dispositivo-cine”). Hace treinta o cuarenta años, esta teoría ponía al alcance de los principales fabricantes de la industria cinematográfica norteamericana una serie de modos de operar, cuyo uso era sólo facultativo. Hoy se ha vuelto palabra de ley en la economía de la cultura. El guionista aprende de los principios básicos de la dramaturgia, aun cuando en ésta no existan reglas absolutas, sino más bien esquemas orientadores de trabajo. La bibliografía de manuales y métodos para escribir guiones de cine y televisión es inmensa. En principio, resulta fácil distinguir entre una escuela americana -o de Hollywood-y una escuela europea. Muchos de esos textos son usados por las escuelas y talleres de guion en todo el mundo. Su elección da cuenta del perfil de guionista que se quiere 
formar, y con ello, parte de los principios inspiradores que sostienen cada proyecto académico. No obstante el predominio de esas fórmulas probadas, en los últimos años se advierte un cambio en la manera de escribir guiones que recuerda a los que se han producido en el teatro o la literatura, donde se abandonan fórmulas empleadas por años y se crean nuevas estructuras. Muchos talleres en el mundo hacen uso de metodologías alternativas que buscan apartarse de la forma clásica o estándar de escribir guiones. Algunos recurren a maestros de la cinematografía mundial de la talla del mismo Ruiz o de Andrei Tarkovski, dos casos en donde los procesos de creación son caóticos y no se ajustan a nada conocido.

El estado de la cuestión presentado en estas páginas da el marco suficiente para que los estudios sobre el cine chileno se pregunten sobre las orientaciones epistemológicas o los principios dramatúrgicos que han sido asumidos por los guionistas para su aplicación en el proceso de escritura creativo, o bien constatar la variación que han tenido los modelos de guion asumidos por el cine chileno de ficción desde una perspectiva longitudinal. En relación al nivel (o calidad) de los estudios formales que se reciben en escritura creativa, varios realizadores chilenos coinciden en que "está muy en pañales" y que se privilegia una formación autodidacta (Dittus, "El guion como metodología" 52). No existe una escuela de guion en Chile, y menos un modelo narrativo, como se observa en otros países de la región. La intuición es la mejor amiga de muchos realizadores, cuestión que se visibiliza, sobre todo, en óperas primas. Esta realidad tiene un arraigo histórico: en Chile nunca ha habido una preocupación por el guion y por mucho tiempo se ha buscado algún modelo a seguir. Tras décadas en las que se intentó formar una industria centrada en el melodrama, el guion divagó en esfuerzos personales o en algunos modelos poco efectivos, con visiones más alternativas o en contra de estructuras clásicas (Ibíd.). Las tensiones en torno a la autoría, la originalidad, la calidad de los diálogos o las temáticas de las que se narra dan paso a nuevas colisiones. Ahora son la especialización de directorguionista o el perfil de las audiencias los temas que avalan el presente y futuro del audiovisual chileno. La actividad escritural dista mucho de las exigencias de una industria cada vez más exigente y competitiva. A pesar de ello, nadie discute la necesidad de grandes historias con riesgo, dedicación y honestidad. Sin embargo, no existe una única fórmula.

A partir de los formatos más clásicos y las escuelas alternativas, el análisis comparado podría arrojar interesantes datos respecto a si, siguiendo esa fórmula o apartándose de ella, la industria audiovisual en Chile podría asegurar su viabilidad financiera y consolidar un desarrollo estratégico. Un estudio llevado a cabo por la Universidad Católica de Chile (Fuenzalida y Julio, Panorama del audiovisual chileno) respecto de la permanencia en pantalla de los estrenos chilenos, desmiente el juicio que dice que la mayoría de las películas chilenas son sacadas a la primera semana de exhibición en las salas. En el informe del año 2009 aparecía que 12 de las 14 películas chilenas estrenadas permanecieron de 3 a 12 semanas en cartelera. En el año 2010, solo 5 de los 15 estrenos 
chilenos estuvieron 1 semana y se debió a su baja asistencia. Las 10 restantes estuvieron entre 2 y 24 semanas. La carencia de estudios cualitativos sobre la estructura del relato le ha impedido ver a la industria la relación entre esa permanencia con el modelo de guion de esas películas y los estándares profesionales de creación. Pareciera, entonces, que es pertinente que el guionista conozca todo el saber acumulado que existe sobre el arte del guion y decida, luego, si quiere desafiar sus reglas.

\section{Referencias}

Aranda, Daniel y Fernando de Felipe. Guion audiovisual. Barcelona: UOC, 2006. Medio impreso.

Aristóteles. Poética. Trad. Eilhard Aschlesinger. Buenos Aires: Losada, 2006. Medio impreso.

Barthes, Roland. Análisis estructural del relato. Trad. Beatriz Dorriots. Puebla: Premia, 1982. Medio impreso.

Blacker, Irwin. Guía del escritor de cine y televisión. Navarra: Eunsa, 1993. Medio impreso. Blaug, Mark. "Where Are we Now in Cultural Economics". Journal of Economic Surveys 15, 2 (2001): 123-143. Medio impreso.

Brenes, Carmen Sofía. "Buenos y malos personajes. Una diferencia poética antes que ética”. Revista de Comunicación 11 (2012): 7-23. Medio impreso.

---. "Quoting and Misquoting Aristotle’s Poetics in Recent Screenwriting Bibliography”. Comunicación y Sociedad 2 (2014): 55-78. Medio impreso.

Buci-Glucksmann Christine. Conversaciones con Raúl Ruiz. Santiago: Universidad Diego Portales, 2003. Medio impreso.

Campbell, Joseph. El héroe de las mil caras. Trad. Luisa Josefina Hernández. México: Fondo de Cultura Económica, 1984. Medio impreso.

---. El poder del mito. Trad. César Aira. Barcelona: Emecé, 1991. Medio impreso.

Carriere, Jean Claude y P. Bonitzer. Práctica del guion cinematográfico. Barcelona: Paidós, 1991. Medio impreso.

Chion, Michel. Cómo se escribe un guion. Madrid: Cátedra, 1989. Medio impreso.

Dittus, Rubén. "El dispositivo-cine como constructor de sentido: el caso del documental político”. Cuadernos. Info 33 (2013): 77-87. Medio impreso.

---. "El guion como metodología: el cine chileno en opinión de sus realizadores". $V$ Encuentro de Investigación sobre Cine Chileno y Latinoamericano, Santiago, Centro Cultural La Moneda. 28-30 de abril de 2015. Medio impreso.

---. "El viaje del héroe en el cine chileno actual: propuesta metodológica”. IV Encuentro de Investigación sobre cine chileno y latinoamericano. Santiago, 23-26 abril de 2014. Medio impreso.

---. "Radiografía del guionista chileno: análisis cuantitativo sobre el oficio de escribir para cine”. II Congreso de la Asociación Chilena de Investigadores en Comuni- 
cación (2015). 5-7 de noviembre, Universidad Católica del Norte, Antofagasta. Medio impreso.

Durlauf, Steven \& Lawrence Blume. The New Palgrave Dictionary of Economics III. Hampshire: Palgrave MacMillan, 2008. Medio impreso.

Field, Syd. El libro del guion. Trad. Marta Heras. Madrid: Plot, 2004. Medio impreso. ---. El manual del guionista. Trad. Marta Heras. Madrid: Plot, 1995. Medio impreso. Frey, Bruno. La economía del arte. Barcelona: La Caixa, 2000. Medio impreso.

Fuenzalida, Valerio y Pablo Julio. Panorama del audiovisual chileno. Santiago: Pontificia Universidad Católica de Chile, 2011. Medio impreso.

Galemiri, Benjamín. Guion: dramaturgia para el cine. Material de docencia. Programa de Diplomado en Guion Cinematográfico. Universidad de Chile, 2012. Medio impreso.

García-Noblejas, Juan José. Poética del texto audiovisual: Introducción al discurso narrativo de la imagen. Pamplona: Eunsa, 1982. Medio impreso.

Greimas, Algirdas. Semántica estructural. Trad. Marcos Martínez Hernández. Madrid: Gredos, 1987. Medio impreso.

Lubbert, Orlando. Guion para un cine posible. Santiago: Uqbar editores, 2009. Medio impreso.

McKee, Robert. El Guion. Trad. Jessica Lockhart. Barcelona: Alba, 2002. Medio impreso. Palma, Luis. "Mercado del arte y economía de la cultura”. Cuadernos de Economía de la Cultura 3 (enero-junio 2004): Oikos, Observatorio Andaluz para la economía de la cultura y el desarrollo. Medio impreso.

Parker, Philip. Arte y ciencia del guion. Trad. Jorge Conde. Barcelona: Manontroppo, 2012. Medio impreso.

Propp, Vladimir. Morfología del cuento. Trad. del francés de F. Díez del Corral. Madrid: Akal, 2011. Medio impreso.

Ruiz, Raúl. Ruiz. Entrevistas escogidas-bibliografía comentada. Santiago: Universidad Diego Portales, 2013. Medio impreso.

---. Poéticas del cine. Santiago: Universidad Diego Portales, 2013. Medio impreso.

Sánchez, Cristián. Aventura del cuerpo. El pensamiento cinematográfico de Raúl Ruiz. Santiago: Ocho libros, 2011. Medio impreso.

Sánchez-Escalonilla. Estrategias de guion cinematográfico. Barcelona: Ariel, 2014. Medio impreso.

Seger, Linda. Cómo convertir un buen guion en un guion excelente. Trad. Marisa Chacón. Madrid: Rialp, 2011. Medio impreso.

Stange, Hans y Claudio Salinas. "Hacia una elucidación del campo de estudios sobre cine en Chile”. Aisthesis 46 (2009): 270-283. Medio impreso.

Trejo, Roberto. Cine, neoliberalismo y cultura. Santiago: Arcis, 2009. Medio impreso. Truby, John. Anatomía del guion. Trad. Elena Villalonga. Barcelona: Alba, 2007. Medio impreso. 
Tubau, Daniel. El guion del siglo 21. Barcelona: Alba, 2011. Medio impreso.

---. Las paradojas del guionista. Barcelona: Alba, 2010. Medio impreso.

Valenzuela, José Ignacio. Taller de escritura de telenovelas. Santiago: Uqbar, 2012. Medio impreso.

Vanoye, Francis. Guiones modelos y modelos de guion. Trad. Antonio López Ruíz. Barcelona: Paidós, 1991. Medio impreso.

Vogler, Christopher. El viaje del escritor. Barcelona: Manontroppo, 2002. Medio impreso.

Wasko, Janet. "La economía política del cine". Cuadernos de Información y Comunicación 11 (2006): 95-110. Medio impreso.

Zallo, Ramón. "La economía de la cultura (y de la comunicación) como objeto de estudio”. Zer 22 (2007): 215-234. Medio impreso.

Recibido: 09 julio 2014

Aceptado: 14 julio 2015 